\title{
An Exploration of Novice Nursing Student's Experiences of Mentoring in Practice Placement Settings in the United Kingdom
}

\author{
*Darren Brand \\ University of Brighton, United Kingdom
}

\begin{abstract}
This study focuses on the experience of new UK student nurses of being mentored in the workplace (placement) setting. There is only limited nursing literature that focuses on the experience of being mentored, whilst there is significant material that examines the role of the mentor. With half of the course being spent in the placement setting, the role of the mentor is pivotal in supporting the student and their learning. Adopting a qualitative design, data was collected through small-group interviews with a cohort of first-year nursing students. Data analysis followed in the form of standard thematic analysis. The Communities of Practice model developed by Lave \& Wenger was applied as a theoretical lens. Two main themes emerged from the analysis process: the process of belonging; and that of developing identity as a learner. Whilst there was consensus with the literature in that it was felt that the mentor had a key role to play in supporting and facilitating learning, the participants also felt that the mentor supported them to settle into the team. Further, it was found that until the learner felt part of the wider placement clinical team, the process of learning may be hindered. An argument is presented advocating better preparation of students for learning in the workplace setting as this will enable them to assimilate better the learning offered by mentors and the wider healthcare team.
\end{abstract}

Keywords: mentor; nurse; placement learning

\section{Introduction and background}

\section{The role of placements in the nursing course}

To become a qualified nurse in the UK, students must study for three years. Half of this time is spent in the university and half in clinical practice, with a total of 2,300 hours in each setting (Nursing \& Midwifery Council, 2008). Whilst the Nursing \& Midwifery Council (NMC) provides no standard or generic definition of a placement, the wider literature speaks of the purpose of a placement being to develop knowledge, skills and values and to become a skilled and confident professional practitioner. This view is supported by a number of authors who argue that placements are vital in the development of practical knowledge and skills (Billett, 2001; Flott \& Linden, 2015; Franklin Torrez \& Krebs, 2012; Guile

*Corresponding Author: Darren Brand, School of Health Sciences, University of Brighton, Darley Road, Eastbourne, BN20 7UR, United Kingdom

Email: d.p.brand@brighton.ac.uk

Journal URL: https://publications.coventry.ac.uk/index.php/pblh

Brand, D. (2020). An exploration of novice nursing student's experiences of mentoring in practice placement settings in the United Kingdom. International Journal of Practice-based Learning in Health and Social Care, 8(1), 73-85. https://doi.org/10.18552/ijpblhsc.v8i1.573

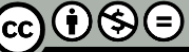

(C) BY ND (C) 2020 Darren Brand. This Open Access article is distributed under the terms of the Creative Commons Attribution Attribution-Non-Commercial No Derivatives 4.0 International License (https://creativecommons.org/licenses/by-nc-nd/4.0/ ), which permits unrestricted non-commercial use, distribution, and reproduction in any medium, provided the original work is properly cited and is unaltered. 
\& Griffiths, 2000; Woodward, 2013). Other literature emphasises the importance of supporting students in practice because of the challenges posed by entering complex and potentially challenging clinical areas (Andrew et al., 2009; Manning et al., 2009; Mulholland et al., 2008; Pryjmachuk et al., 2009; Watson et al., 2009).

\section{Mentor selection and training}

At the time of writing (2019), the NMC has begun the process of introducing new practice support roles for nursing students. Mentors are to be replaced by two new positions: a Practice Supervisor, who will support learning and facilitate opportunities to engage in practical clinical learning, and a Practice Assessor who will lead on the assessment requirements (Nursing \& Midwifery Council, 2008). This research was undertaken whilst the mentor role was wholly in existence but the term mentor no longer applies to pre-registration nursing courses starting from September 2019 onwards. In future, the Practice Supervisor will be responsible for what could be viewed as the traditional role of the mentor; this includes responsibility for teaching, providing advice and guidance, and for facilitating learning experiences. The Practice Assessor will lead on assessment requirements.

Whilst there is limited literature that outlines the purpose of a placement (Foster et al., 2015), the NMC is very clear that, whilst in practice, a qualified mentor must be allocated to facilitate the practice learning experience (Nursing \& Midwifery Council, 2008). However, there is no consideration of how learning occurs in practice settings or how mentors can facilitate the process. Instead, learning appears to be taken for granted. Registered nurses can obtain a mentoring qualification by completing an approved mentor preparation module at a university which ensures that they are competent to teach and assess a learner in the practice environment. The mentor holds responsibility for the facilitation of learning, the assessment process and the general welfare of students whilst in the clinical setting.

\section{The concerns that motivated the research}

As lecturers working in a School of Health Sciences, my colleagues and I teach students the theoretical side of nursing. In doing so, I am able to ensure that all students in a cohort group receive the same information, delivered in a relatively uniform style. The mentor's role is perceived as helping students to put theory into practice, although as was noted above, this view is sometimes questioned in the literature: I will return to this in my conclusion. Whilst in the university, a student is supported by many lecturers, whereas the practice mentor-student relationship is 1:1, and as such dependent upon the relationship between the two.

Taking all of the above into consideration, the identified research question was What is the student nurse experience of being mentored during placements? The following section will provide a brief overview of the existing literature surrounding such experience.

\section{Literature review}

My work within the university meant that I was aware there was a wealth of literature available in the field of nurse mentorship, and as a result I wanted specifically to identify material in the field of the 'student experience'. The databases used in the literature search were British Nursing Index (BNI), Cumulative Index for Nursing and Allied Health Literature (CINAHL) and PubMed ${ }^{\circledR}$, as they are recognised, credible databases that are used and consulted widely in the field of nursing. Boolean search operators were employed to increase the likelihood of positive search results.

Four main themes were identified, and are summarised in the remainder of this section.

\section{The role of the mentor}

A qualified and named mentor must be allocated to each nursing student on a placement (Nursing \& Midwifery Council, 2008; 2010), in either the acute environment (hospital) or the community environment (primary care - GP surgery, district nursing, etc.). 
Staff not holding a mentor qualification may act in an associate or 'buddy' mentor capacity, supporting both the main mentor and the learner, but in nursing practice, mentors are seen as the main facilitators of learning who act as a signpost by assisting the learner to identify educational opportunities to develop their nursing practice (Nursing \& Midwifery Council, 2008). Allocation of mentors to students is managed internally by the placement setting (Royal College of Nursing, 2007). Literature that outlines the requirements of a mentor is minimal; this concern highlights the need for research into the experiences of nursing students, although there is a strong body of literature (Casey \& Clark, 2011; McIntosh et al., 2014; Rylance et al., 2017; Walsh, 2010) that looks at the experiences of mentors in their role. For learners, it is of importance that the experience of developing nursing skills in placements is a positive one, and this responsibility aligns closely with the mentor.

Recent literature sees the mentor having two functions: teacher and assessor (Cooper et al., 2015; Helminen et al., 2014; Mead et al., 2011; Price, 2012). This view does not fit with the traditional view of mentoring, where assessment is not viewed as the responsibility of a mentor (Clutterbuck, 2004). The literature identifies the student's expectations; in this light, a nursing mentor's role could be viewed as being a combination of teacher, assessor, expert in practice, provider of pastoral support and curriculum link (Cooper et al., 2015; Gale et al., 2016; Nursing Times Contributor, 2014; Materne et al., 2017; McIntosh et al., 2014; Mead et al., 2011).

\section{Purpose of the mentor}

There is recognition within the literature that the mentor acts as a role model, exemplifying good nursing practice, whilst also delivering and facilitating learning (Barry et al., 2016; Foster et al., 2015; Gale et al., 2016; Henderson et al., 2012; Ness et al., 2010). The allocated mentor holds responsibility for a number of areas whilst working alongside a student nurse: these include the induction and orientation to the placement setting, including general welfare (storage of belongings etc.) and orientation to fire exits and emergency equipment (Royal College of Nursing, 2006). They also take responsibility for arrangement of initial meetings and interviews, the timely completion of documentation, such as the learning contract agreement and the placement plan, and the facilitation of learning opportunities, teaching and assessment of clinical skills and the NMC expected competencies. Feedback is a further integral part of the role of the mentor, both in terms of communicating with the learner and colleagues who may be involved in supporting the learner, as well as with the university team (Duffy, 2013; Foster et al., 2015; Ness et al., 2010; Walsh, 2010). Whilst this is regarded as the role of the mentor, literature suggests that mentors often lack the confidence to provide feedback. This is concerning, as the mentor has already been identified as the central support function in the placement setting (Duffy, 2013; Materne et al., 2017; Mead et al., 2011).

Some placements utilise a team-mentoring system, whereby the learner works alongside the whole team to benefit from a range of experiences and ways of approaching the same task. However, the NMC still requires a named individual mentor to maintain overarching responsibility for the learning in that placement (Nursing \& Midwifery Council, 2008). With the introduction of Practice Supervisors and Assessors, named individuals will still be necessary (Nursing \& Midwifery Council, 2018).

\section{Experiences of students in practice}

It is acknowledged in the literature (Hinton, 2016; Levett-Jones et al., 2015; Walker et al., 2014) that the first placements a student nurse attends are a critical point and a time of high emotions. There are examples (Baglin \& Rugg, 2009; Collin et al., 2011; D'Souza et al., 2015; Flott \& Linden, 2015; Ironside et al., 2014) that characterise the student experience of mentoring as being both positive and negative. This is because, for many students, this is their initial experience of delivering care, and expectations and anxiety levels may be high.

Students sometimes observe that the placement learning is the means by which theory is translated into practice, helping to contextualise the university-based element of the course (Helminen et al., 2014; Rylance et al., 2017). They also suggest that the quality of the mentoring experience can make or break the placement overall (Gillespie, 2017). Some students may be allocated the most senior person in the department as their mentor, and in such cases frequently comment that they felt ignored or neglected, as 
the mentor was too busy with other responsibilities. The literature regularly comments on the difficulty that can arise in relation to time pressures(Foster et al., 2015; Gale et al., 2016; McCallum et al., 2016; McIntosh et al., 2014; Moran \& Banks, 2016; Thomas et al., 2015).

Students also speak of the frustration of busy and unpredictable environments that can impact upon the amount of time they spend with mentors, preventing such tasks as getting documentation and review interviews from being completed in a timely fashion (D'Souza et al., 2015; Duffy, 2013; Flott \& Linden, $\underline{2015)}$.

\section{Placement definitions}

Placement learning is seen as the process whereby knowledge and skills are acquired in the workplace by formal or informal means (Avis, 2010; Collin et al., 2011). The nursing literature suggests that approximately $80 \%$ of learning in the workplace occurs through informal processes, such as networking, coaching and mentoring as a direct result of work-related interactions (Collin et al., 2011; Doornbos et al., 2008; Felstead et al., 2005; Fenwick, 2008; Yeo, 2008). This involves learning in different contexts or through different activities from those encountered at the university.

However, there is minimal literature about how a student should prepare to learn in a placement (Cahill, 1996; Jokelainen et al., 2011; Royal College of Nursing, 2006). The Royal College of Nursing (RCN) toolkit for students offers practical advice, although this is somewhat dated and of limited use to students in preparing to learn as it offers suggestions such as making contact with the placement in advance to arrange shifts, and it again takes learning for granted. The nursing literature does not provide students with advice on how to learn whilst in the work-place, which is disappointing when the placement element constitutes a mandatory half of the overall learning experience.

\section{Methods}

Careful consideration was given to the most appropriate method for data collection, with group interviews, focus groups, observations and action research all considered.

Though a number of approaches to data collection would have been appropriate, small group interviews were felt to be the most effective as, with very new students, the ability to relate to peers within the interviews was seen as a positive, and as a way of validating their own early placement experiences (Denscombe, 2014). Small group interviews were also utilised by some of the studies that have been referred to within the literature review where they proved an effective method of data collection (Foster et al., 2015).

The group interviews were undertaken in a simulation room that was fitted with ceiling-mounted cameras. The ability to video record was of significance, as it afforded a number of benefits. The researcher was able to observe body language, which helped with the validation of responses (Kleinman \& Copp, 1993). Video recording assists with the transcription process when using an audio recorder (Hepburn \& Bolden, 2017). As the cameras were ceiling mounted, the group very quickly forgot they were there.

Bryman (2012) highlights the benefit of interviews and the ability to ask participants the same questions about specified subject matter. The research was intended to explore the views of those participating, so a grid of questions was used to ensure the interview retained focus but at the same time allowed flexibility to deepen my understanding of a response if needed. Bryman identifies errors that can occur in the interview process in relation to the interviewee misunderstanding the questions. Clarification was provided if a question was not understood by the participant. The questions that were used as prompts for the group interview arose from the themes identified within the literature review, namely:

- The role of the mentor;

- The purpose of the mentor;

- Experiences of being mentored in the clinical placement. 
Ethical approval for this study was granted at tier two of the School of Education / College of Social Sciences ethics panel (University of Brighton, 2015). A participant information sheet was provided, and each nursing student participating signed a consent form.

Participants were student nurses, currently enrolled on the BSc (Hons) Nursing course to become a registered nurse. Seven students, recruited through a 'convenience' approach, took part in the group interview and were recruited from the newest cohort, to express the thoughts and opinions of experiences of being mentored in practice before they became more experienced and had developed confidence and resilience skills. A convenience approach was employed as this research was a pilot study, and student nurses were invited to participate to share their experiences of being mentored based upon their availability (Flick, 2014).

Standard thematic analysis was used to extract themes from the data, a recognised method of working with qualitative data (Saldaña, 2016). (Whilst it is acknowledged that other approaches to data analysis were available, e.g. grounded theory, they were not deemed appropriate as the literature review had identified directly relevant themes which would provide a framework for gaining insight into, and making sense of, the experiences of participants.) Thematic analysis within qualitative research is beneficial in that it pinpoints patterns or themes within the data that are helpful in describing the subject being focused upon, and has been successfully used in numerous studies linked with understanding experiences of learners (Braun \& Clarke, 2006; Cahill, 1996; Courtney-Pratt et al., 2012; Houghton et al., 2013; Wallin et al., 2013).

The final stage of this process was to apply a theoretical lens to provide a deeper level of analysis, namely the Communities of Practice model and concept of Legitimate Peripheral Participation devised by Lave and Wenger (1991). The model was initially developed as a theory of learning but evolved to become part of the wider field relating to knowledge management. According to Wenger, learning is the key to human identity, and he views this through social participation. Nursing students seek to create their own identity, and interaction and engagement with a placement area or a community allows such processes to occur. Wenger notes that learners will hold a desire to develop skills if those they are interacting with have similar skills (Wenger, 1998; Wenger et al., 2002).

\section{Findings}

This section will examine the data collected and the literature in relation to the expectations of the nursing profession of mentoring in nursing placements.

\section{Traditional mentoring role}

In the small group interviews, participants spoke about the importance of a mentor to fill the roles of teacher, facilitator and role model.

My mentor was great - just the type of nurse I aspire to become.

My mentor was a fantastic teacher - they knew everything and I never felt afraid to ask questions.

My mentor became almost a friend - I was able to ask questions, and they had a knack of being there when I needed them, and a way of making sure I was in the right place at the right time to learn new things.

The literature review section has already identified these aspects of mentoring as being traditional. Surprisingly there was less attachment made to the role of the assessor. When assessment was mentioned, the main area of significance was that students noted that the mentor became "more serious". Participants spoke about expecting the mentor to provide a quality placement experience, and to ensure that the learning activities provided are relevant and aligned with the learning they perceive to be associated to the role of the nurse. The students' expectations of their mentor aligns with the work of Billett $(2001 ; \underline{2002})$. 


\section{Difficulty grasping 'unstructured' learning opportunities}

Billett (2001) argues that learning in the workplace is structured by historical, cultural and situational factors, which influence both the type and quality of learning. These factors have an effect on the activities that a learner participates in and through which they learn; this links to peripheral participation and Wenger's work. For this reason, Billett states that learning in the workplace, or placement, cannot be labelled as 'informal'. The participants in my study noted that the learning opportunities in practice occur often without notice, and that they felt they had to be in the right place at the right time:

I found that I had to be quite adaptable. Sometimes I found out about opportunities to learn new skills or observe new things after they had happened.

It took me a while to adapt to practice, as in the university the learning was clearly set out for us, it wasn't the case in placement.

This second quotation is particularly significant. It suggests that whilst students rely on a mentor to undertake the role of teacher and facilitator, they struggle to adapt to the fact that learning is not always obvious in the same way that it is in the university setting, where clearly articulated learning goals are the primary focus of activity by lecturer and student.

\section{Belonging / acceptance within a team}

An area of significant correlation between the data and the literature is the theme of belonging, and which also aligns closely with the theoretical perspective of Communities of Practice. Although this was the shortest placement that the students would complete (five weeks), all of the participants spoke about the importance of feeling part of the wider team, and the significance of this for learning. The learners spoke about how, in the early part of the placement, time was spent trying to feel accepted and welcomed by the team, and wanting to make a good impression:

I wanted the team to like me and to support me whilst I was on the ward.

I didn't want to be a burden to my mentor as I knew they were busy professionals, but it was important to my learning that I felt part of the team.

This was a new experience to me, and I felt that I learnt much more once I had settled into the placement and grew more comfortable with the people around me, not just my mentor.

The participants attached importance to the process of making a good impression and not wanting to appear to be overly confident, and they wanted to ensure that they gained as much learning and new practical knowledge from their mentors as possible:

Although I have worked on a ward before, I didn't tell my mentor this as I wanted to be treated the same as someone with no experience.

Although I didn't need to, I made sure that I worked every shift with my allocated mentor, so that they had every opportunity to get to know my capabilities.

Although they spoke of being aware of not appearing overly confident, the body language observed when the participants were speaking spoke differently to me. I gained the impression that the concern was more about a lack of confidence at this stage, and that the support of the mentor was important to them to feel supported and to progress successfully through the placement. Confidence was a theme that arose throughout the interview, either directly or indirectly, and this manifested itself in a number of ways.

\section{Being part of a learning community - gaining meaning of the role of the nurse}

Conversely, students appeared to reject the suggestion that they learnt from day one in a tacit nature, and seemed not to appreciate how learning could take place informally through conversations with mentors and patients, or through the observation of others. The issue of time also arose in the interviews, and it 
was evident that many of the group had not fully anticipated that their mentor's primary role was to deliver patient care. Some were surprised by the sometimes limited time to be spent undertaking what they called 'structured learning'. Whilst the group understood the reasons for this, there appeared to be no link made between the time made available for mentoring, and the more time-consuming role they had in the team. For example, some student nurses were allocated mentors who were senior in the team (e.g. manager / matron responsibilities), and others were more junior staff nurses.

I knew my mentor would be a busy person, but I was surprised at just how much they had to do - I was impressed by the way they juggled patient care and teaching.

My mentor was very busy all of the time, and I had to keep myself busy at certain times... they didn't always have time for me... at least that is how it felt.

As I have suggested in the previous section, I would infer that student nurses almost expect there to be a structured curriculum in the placement setting. They have become accustomed to this in the early days of the course whilst in university and as such they could be seen as looking for an overtly structured learning process in practice. What they actually experience may be viewed by them as somewhat chaotic. This chaos may not be fully understood or interpreted until they feel they are fully settled in the team - at which point the strange begins to become familiar. A lack of structure may be viewed in the clinical setting, and students may need explanations of the roles held by the wider team. It seems that nursing students appear unable to identify opportunities to learn until they begin to understand the structure of the working practices in which those opportunities occur.

As adult learners, there is an expectation that students seek out learning opportunities and are responsible for directing their own needs. The data suggests that this requirement is very new to them, and that with time they will become accustomed to seeking out other members of the team. After one placement experience, there was clearly an expectation that the mentor would lead on all activities relating to the needs of the learner. This links to another theme that will be discussed later in this section relating to 'surrogate parent' roles. It also links to the work of Billett (1996) and his notion of a learning curriculum.

I would suggest that sometimes the focus of the student is less about developing their understanding of what it is to be a nurse and more about ensuring that what they perceived to be 'structured' learning was taking place. Interestingly, there was little mentioned in the group interview about getting skills signed off, or about assessment.

\section{Surrogate parenting}

One theme that was identified, but did not appear to link with the literature review directly, was the need for the mentor to play a 'surrogate parent' role. On a number of occasions, participants spoke of the need to be 'looked after' or 'taken care of', with the expectation that the mentor would act as the individual who would make arrangements and sort out any issues as they arose whilst in practice settings. Frequent mention was made of the expectation that the mentor should take the lead in the process of settling the student in to the placement, by leading on activities such as team introductions, arranging opportunities to spend time with other members of the multidisciplinary team, and leading on documentation. In this way, participants have expressed the traditional view of the teacher-learner relationship whereby the teacher makes learning explicit for the (childlike) learner. This contrasts with the view of the learner as adult, expected to take responsibility for their own learning.

The literature related to nursing appears to overlook this; it may be that studies tend to involve more experienced students, with a number of placements under their belt, whereas my study involved new students at the end of their first placement. Having considered this aspect at a deeper level, I would question whether they may be looking for a surrogate parent figure, or a mentor in the truest sense of the term. It was very evident from the ways in which respondents spoke that they expected their mentor to provide a close supporting role. This is recognised as regression in the literature, where there is a supporting 'adult' (mentor in this sense) available to mitigate any anxiety that may be held. For all the students interviewed, this was their first placement and from the language observed - both spoken and body positioning - it was clear that there was a level of anxiety for all: 
I didn't know fully what to expect, and... um, I was very nervous beforehand. I hoped that my mentor would be kind and would look after me.

I didn't really sleep beforehand... and, err... I hoped that my mentor stayed with me and wouldn't leave me on my own. That was my nightmare.

After a couple of shifts, I felt more comfortable, but I worried what would happen if my mentor called in sick. Who would look after me then?

This also aligns closely to Billett's (2001) work in relation to being a newcomer in the workplace, and the challenges that this presents. He discusses the notion of the workplace or placement as a centre of inquiry, and the role 'old-timers' play in supporting newcomers to the setting.

\section{Discussion and conclusion}

In terms of the research question, the participants found the mentoring experience to be a positive one. Their feedback indicated that mentors were supportive in their roles, and were viewed by students as being very knowledgeable and as role models. It must be noted that the students involved in this study were very junior, having only participated in one placement of four weeks' duration at the start of their course. As such, these views cannot be seen as representative of all students on the course, nor indeed of peers in the same cohort. It would appear that expectations of mentors were met, whilst noting that opportunities to spend quality time with mentors were limited. This aligned with the literature (Cooper et al., 2015; Gidman et al., 2011; McCallum et al., 2016; Thomas et al., 2015), as mentors are not allocated any protected time for their mentoring role and patient care is always their main priority.

The data collected demonstrated the importance a nursing student in the early part of their course attaches to feeling a sense of belonging. This was an aspect that had not been identified in the themes arising from the literature review, and was felt to be significant. The participants spoke of the key role that a mentor had to play in this process, and they felt that the mentors with whom they had worked were very effective in facilitating this process.

The students believed that learning took place once the feeling of belonging had developed and they felt part of the team in which they were placed. I hope that future research can further explore another aspect of this theme, that of identity. Student nurses find themselves in a position whereby they have to move between different identities. Whilst they are in the university setting, they regard themselves as students of the university. Once they move out into placements, they have to undergo a transformative process and act in a novice practitioner identity. This may be challenging and needs further exploration. Having spoken to new students within this study, I conclude that there is a need to provide students with training on how to undertake these varying roles. In the practice setting, student nurses are expected by their patients to deliver care and act in a professional fashion. Likewise, they need to be able to recognise learning opportunities that may not be overtly clear to them, especially as for many individuals, this may be their first time in a workplace environment.

Expectations of mentors centred on what may be termed 'traditional' elements of mentoring, those of teacher and guide, with the participants in this study not necessarily viewing their mentors as assessors. The data analysis noted the fact that it may be that novice nursing students view mentors in the 'traditional' teacher role. Literature (Rainbird et al., 2004) states that workplace learning is very different from learning in other settings, and in particular the process of learning in work is very different from learning in a formal education setting. For nursing students, they are forced to combine both from the outset of the course.

The data collected in this research demonstrates a need to better prepare student nurses for practice. This may be connected to the fact that a structured learning curriculum, with explicit learning outcomes, is not presented in the placement setting as it is in the university setting. As discussed previously, this links well with Billett's work (1996) around a learning curriculum. If students need to see a more structured process of learning, with clear objectives set out in the early days, a mentor has a key role to identify such learning opportunities. Although the issue of limited time with mentors has already been identified, future 
research may be beneficial in terms of exploring how spending time early in the placement creating a defined learning plan could help the student. The research highlights a healthy learning culture, denoted by a positive relationship between the mentors and nursing students involved in this study. Though a small study, and as a result the findings can be viewed as more limited, those interviewed stated that they felt supported and they valued the importance of a mentor in their education. There is a need for future research into this area, and in particular it would be prudent to explore the implementation of the new NMC roles - practice supervisors and assessors - in order to establish whether a student felt the level of support available to them had changed in any way.

\section{ORCID}

Darren Brand https://orcid.org/0000-0002-9663-2832

\section{References}

Andrew, N., McGuinness, C., Reid, G., \& Corcoran, T. (2009). Greater than the sum of its parts: Transition into the first year of undergraduate nursing. Nurse Education in Practice, 9(1), 13-21. https://doi.org/10.1016/j.nepr.2008.03.009

Avis, J. (2010). Workplace learning, knowledge, practice and transformation. Journal for Critical Education Policy Studies, 8(2), 165-193. http://www.jceps.com/archives/647

Baglin, M. R., \& Rugg, S. (2009). Student nurses' experiences of community-based practice placement learning: A qualitative exploration. Nurse Education in Practice, 10(3), 144-152. https://doi.org/10.1016/j.nepr.2009.05.008

Barry, D., Houghton, T., \& Warburton, T. (2016). Supporting students in practice: Leadership. Nursing Standard, 31(4), 46-53. https://doi.org/10.7748/ns.2016.e9669

Billett, S. (1996). Towards a model of workplace learning: The learning curriculum. Studies in Continuing Education, 18(1), 43-58. https://doi.org/10.1080/0158037960180103

Billett, S. (2001). Workplace affordances and individual engagement at work. Griffith University, Queensland.

https://www.avetra.org.au/data/Conference_2001_pres./17_Stephen_Billett_paper.pdf

Billett, S. (2002). Critiquing workplace learning discourses: Participation and continuity at work. Studies in the Education of Adults, 34(1), 55-67. https://doi.org/10.1080/02660830.2002.11661461

Braun, V., \& Clarke, V. (2006). Using thematic analysis in psychology. Qualitative Research in Psychology, 3(2), 77-101. https://doi.org/10.1191/1478088706qp063oa

Bryman, A. (2012). Social research methods (4th ed.). Oxford University Press.

Cahill, H. A. (1996). A qualitative analysis of student nurses' experiences of mentorship. Journal of Advanced Nursing, 24(4), 791-799. https://doi.org/10.1046/j.1365-2648.1996.25618.x

Casey, D. C., \& Clark, L. (2011). Roles and responsibilities of the student nurse mentor: An update. British Journal of Nursing, 20(15), 933-937. https://doi.org/10.12968/bjon.2011.20.15.933

Clutterbuck, D. (2004). Everyone needs a mentor: Fostering talent in your organization (4th ed.). Chartered Institute of Personnel \& Development.

Collin, K., Sintonen, S., Paloniemi, S, \& Auvinen, T. (2011). Work, power and learning in a risk filled occupation. Management Learning, 42(3), 301-318. https://doi.org/10.1177/1350507610394411 
Cooper, J., Courtney-Pratt, H., \& Fitzgerald, M. (2015). Key influences identified by first year undergraduate nursing students as impacting on the quality of clinical placement: A qualitative study. Nurse Education Today, 35(9), 1004-1008. https://doi.org/10.1016/j.nedt.2015.03.009

Courtney-Pratt, H., Fitzgerald, M., Ford, K., Marsden, K., \& Marlow, A. (2012). Quality clinical placements for undergraduate nursing students: A cross-sectional survey of undergraduates and supervising nurses. Journal of Advanced Nursing, 68(6), 1380-1390. https://doi.org/10.1111/j.1365-2648.2011.05851.x

Denscombe, M. (2014). The good research guide for small-scale social research projects (5th ed.). Open University Press.

Doornbos, A. J., Simons, R. -J., \& Denessen, E. (2008). Relations between characteristics of workplace practices and types of work-related learning: A survey study among Dutch Police. Human Resource Development Quarterly, 19(2), 129-151. https://doi.org/10.1002/hrdq.1231

D'Souza, M. S., Karkada, S. N., Parahoo, K., \& Venkatesaperumal, R. (2015). Perception of and satisfaction with the clinical learning environment among nursing students. Nurse Education Today, 35(6), 833-840. https://doi.org/10.1016/j.nedt.2015.02.005

Duffy, K. (2013). Providing constructive feedback to students during mentoring. Nursing Standard, 27(31), 50-56. https://doi.org/10.7748/ns2013.04.27.31.50.e7334

Felstead, A., Fuller, A., Unwin, L., Ashton, D., Butler, P., \& Lee, T. (2005). Surveying the scene: Learning metaphors, survey design and the workplace context. Journal of Education and Work, 18(4), 359-383. https://doi.org/10.1080/13639080500327857

Fenwick, T. (2008). Understanding relations of individual-collective learning in work: A review of research. Management Learning, 39(3), 227-243. https://doi.org/10.1177/1350507608090875

Flick, U. (2014). An introduction to qualitative research (5th ed.). Sage.

Flott, E. A., \& Linden, L. (2015). The clinical learning environment in nursing education: A concept analysis. Journal of Advanced Nursing, 72(3), 1-13. https://doi.org/10.1111/jan.12861

Foster, H., Ooms, A., \& Marks-Maran, D. (2015). Nursing students' expectations and experiences of mentorship. Nurse Education Today, 35(1), 18-24. https://doi.org/10.1016/j.nedt.2014.04.019

Franklin Torrez, C. A., \& Krebs, M. M. (2012). Expert voices: What cooperating teachers and teacher candidates say about quality student teaching placements and experiences. Action in Teacher Education, 34(5-6), 485-499. https://doi.org/10.1080/01626620.2012.729477

Gale, J., Ooms, A., Sharples, K., \& Marks-Maran, D. (2016). The experiences of student nurses on placements with practice nurses: A pilot study. Nurse Education in Practice, 16(1), 225-234. https://doi.org/10.1016/j.nepr.2015.08.008

Gidman, J., McIntosh, A., Melling, K., \& Smith, D. (2011). Student perceptions of support in practice. Nurse Education in Practice, 11(6), 351-355. https://doi.org/10.1016/j.nepr.2011.03.005

Gillespie, M. (2017). Student nurse preferences for their first clinical experience: A thematic analysis. British Journal of Nursing, 26(2), 104-108. https://doi.org/10.12968/bjon.2017.26.2.104

Guile, D., \& Griffiths, T. (2000). Learning through work experience. Journal of Education and Work, 14(1), 113-131. https://doi.org/10.1080/13639080020028738 
Helminen, K., Tossavainen, K., \& Turunen, H. (2014). Assessing clinical practice of student nurses: Views of teachers, mentors and students. Nurse Education Today, 34(8), 1161-1166. https://doi.org/10.1016/j.nedt.2014.04.007

Henderson, A., Cooke, M., Creedy, D. K., \& Walker, R. (2012). Nursing students' perceptions of learning in practice environments: A review. Nurse Education Today, 32(3), 299-302. https://doi.org/10.1016/j.nedt.2011.03.010

Hepburn, A., \& Bolden, G. B. (2017). Transcribing for social research. Sage.

Hinton, J. (2016). An exploration of Operating Department Practice students' experiences of placement support during their first perioperative clinical placement. Nurse Education in Practice, 16(1), 242-250. https://doi.org/10.1016/j.nepr.2015.09.005

Houghton, C. E., Casey, D., Shaw, D., \& Murphy, K. (2013). Students' experiences of implementing clinical skills in the real world of practice. Journal of Clinical Nursing, 22(13-14), 1961-1969. https://doi.org/10.1111/jocn.12014

Ironside, P. M., McNelis, A. M., \& Ebright, P. (2014). Clinical education in nursing: Rethinking learning in practice settings. Nursing Outlook, 62(3), 185-191. https://doi.org/10.1016/j.outlook.2013.12.004

Jokelainen, M., Turunen, H., Tossavainen, K., Jamookeeah, D., \& Coco, K. (2011). A systematic review of mentoring nursing students in clinical placements. Journal of Clinical Nursing, 20(19-20), 2854-2867. https://doi.org/10.1111/j.1365-2702.2010.03571.x

Kleinman, S., \& Copp, M. A. (1993). Emotions and fieldwork. Sage.

Lave, J., \& Wenger, E. (1991). Situated learning: Legitimate peripheral participation. Cambridge University Press.

Levett-Jones, T., Pitt, V., Courtney-Pratt, H., Harbrow, G., \& Rossiter, R. (2015). What are the primary concerns of nursing students as they prepare for and contemplate their first clinical placement experience? Nurse Education in Practice, 15(4), 304-309. https://doi.org/10.1016/j.nepr.2015.03.012

Nursing Times Contributor. (2014). Sustaining and assuring the quality of student nurse mentorship: What are the challenges? Nursing Times, 110. https://www.nursingtimes.net/roles/nurseeducators/sustaining-and-assuring-the-quality-of-student-nurse-mentorship-what-are-thechallenges-22-08-2014/

Manning, A., Cronin, P., Monaghan, A., \& Rawlings-Anderson, K. (2009). Supporting students in practice: An exploration of reflective groups as a means of support. Nurse Education in Practice, 9(3), 176-183. https://doi.org/10.1016/j.nepr.2008.07.001

Materne, M., Henderson, A., \& Eaton, E. (2017). Building workplace social capital: A longitudinal study of student nurses' clinical placement experiences. Nurse Education in Practice, 26, 109-114. https://doi.org/10.1016/j.nepr.2017.07.007

McCallum, J., Lamont, D., \& Kerr, E. -L. (2016). First year undergraduate nursing students and nursing mentors: An evaluation of their experience of specialist areas as their hub practice learning environment. Nurse Education in Practice, 16(1), 182-187.

https://doi.org/10.1016/j.nepr.2015.06.005 
McIntosh, A., Gidman, J., \& Smith, D. (2014). Mentors' perceptions and experiences of supporting student nurses in practice. International Journal of Nursing Practice, 20(4), 360-365. https://doi.org/10.1111/ijn.12163

Mead, D., Hopkins, A., \& Wilson, C. (2011). Views of nurse mentors about their role. Nursing Management, 18(6), 18-23. https://doi.org/10.7748/nm2011.10.18.6.18.c8716

Moran, M., \& Banks, D. (2016). An exploration of the value of the role of the mentor and mentoring in midwifery. Nurse Education Today, 40(May), 52-56. https://doi.org/10.1016/j.nedt.2016.02.010

Mulholland, J., Anionwu, E. N., Atkins, R., Tappern, M., \& Franks, P.J. (2008). Diversity, attrition and transition into nursing. Journal of Advanced Nursing, 64(1), 49-59. https://doi.org/10.1111/j.1365-2648.2008.04758.x

Ness, V., Duffy, K., McCallum, J., \& Price, L. (2010). Supporting and mentoring nursing students in practice. Nursing Standard, 25(1), 41-46. https://doi.org/10.7748/ns.25.1.41.s55

Nursing \& Midwifery Council. (2008). Standards to support learning and assessment in practice. Nursing \& Midwifery Council.

Nursing \& Midwifery Council. (2010). Standards for pre-registration nursing education. https://www.nmc.org.uk/globalassets/sitedocuments/standards/nmc-standards-for-preregistration-nursing-education.pdf

Nursing \& Midwifery Council. (2018). Realising professionalism: Standards for education and training: Part 2: Standards for student supervision and assessment. https://www.nmc.org.uk/globalassets/sitedocuments/education-standards/student-supervisionassessment.pdf

Price, B. (2012). Key principles in assessing students' practice-based learning. Nursing Standard, 26(49), 49-55. https://doi.org/10.7748/ns2012.08.26.49.49.c9236

Pryjmachuk, S., Easton, K., \& Littlewood, A. (2009). Nurse education: Factors associated with attrition. Journal of Advanced Nursing, 65(1), 149-160. https://doi.org/10.1111/j.13652648.2008.04852.x

Rainbird, H., Fuller, A., \& Munro, A. (Eds.). (2004). Workplace learning in context. Routledge.

Royal College of Nursing. (2006). Helping students get the best from their practice placements. Royal College of Nursing.

Royal College of Nursing. (2007). Guidance for mentors of nursing students and midwives. Royal College of Nursing.

Rylance, R., Barrett, J., Sixsmith, P., \& Ward, D. (2017). Student nurse mentoring: An evaluative study of the mentor's perspective. British Journal of Nursing, 26(7), 405-409. https://doi.org/10.12968/bjon.2017.26.7.405

Saldaña, J. (2016). The coding manual for qualitative researchers (3rd ed.). Sage.

Thomas, J., Jinks, A., \& Jack, B. (2015). Finessing incivility: The professional socialisation experiences of student nurses' first clinical placement, a grounded theory. Nurse Education Today, 35(12), e4-e9. https://doi.org/10.1016/j.nedt.2015.08.022

University of Brighton. (2015). Research ethics policy. University of Brighton. 
Walker, S., Dwyer, T., Broadbent, M., Moxham, L., Sander, T., \& Edwards, K. (2014). Constructing a nursing identity within the clinical environment: The student nurse experience. Contemporary Nurse, 49(1), 103-112. https://doi.org/10.1080/10376178.2014.11081960

Wallin, K., Fridlund, B., \& Thorén, A. -B. (2013). Prehospital Emergency Nursing students' experiences of learning during prehospital clinical placements. International Emergency Nursing, 21(3), 197-203. https://doi.org/10.1016/j.ienj.2012.09.003

Walsh, D. (2010). The nurse mentor's handbook: Supporting students in clinical practice. McGrawHill/Open University Press.

Watson, R., Gardiner, E., Hogston, R., Gibson, H., Stimpson, A., Wrate, R., \& Deary, I. (2009). A longitudinal study of stress and psychological distress in nurses and nursing students. Journal of Clinical Nursing, 18(2), 270-278. https://doi.org/10.1111/j.1365-2702.2008.02555.x

Wenger, E. (1998). Communities of practice: Learning, meaning and identity. Cambridge University Press.

Wenger, E., McDermott, R., \& Snyder, W. M. (2002). Cultivating communities of practice: A guide to managing knowledge. Harvard Business School Press.

Woodward, S. (2013). Student placements need to be positive. British Journal of Neuroscience Nursing, 9(4), 161. https://doi.org/10.12968/bjnn.2013.9.4.161

Yeo, R. K. (2008). How does learning (not) take place in problem-based learning activities in workplace contexts? Human Resource Development International, 11(3), 317-330.

https://doi.org/10.1080/13678860802102609 